\title{
DESENHO TÉCNICO E PERCURSOS PEDAGÓGICOS SIGNIFICATIVOS: UM OLHAR SOBRE APRENDIZAGEM EM CURSOS DE ENGENHARIA
}

\author{
Jefferson Correia da Conceição \\ Universidade do Estado da Bahia \\ Faculdade Santíssimo Sacramento \\ jeffersoncorreia2@gmail.com
}

\begin{abstract}
Resumo
A mediação pedagógica da componente curricular Desenho Técnico, por vezes, é muito confundida por alguns estudantes de engenharia com dificuldades, como algo "muito chato", sem sentido, sem cor, sem atrativos e sem vida. Todavia, podem-se constatar também, mediante algumas ações pedagógicas realizadas em sala de aula, algumas oficinas interdisciplinares, mini cursos e atividades extensionistas, justamente o contrário: beleza, sentido, cor, movimento, criatividade, arte, integrações conceituais e muito envolvimento, pois o público envolvido participa de forma ativa na elaboração do próprio conhecimento, estabelecendo conexões com outras áreas de atuação, com muitas percepções singulares importantes. É possível, de forma lúdica, participativa, movimentada, dinâmica e contextualizada, discutir, exemplificar, elaborar e criar algumas representações gráficas - desenhos projetivos, com base em alguns conceitos e percepções prévias dos estudantes, que estão presentes na vida cotidiana, de forma geral, baseados nos seguintes conteúdos - ponto, simetria, sólidos geométricos, poliedros, formas regulares e irregulares, ângulos, arcos, dentre outros, por intermédio de uma prática pedagógica amparada pela ludicidade e pela criatividade, uma vez que, as atividades se tornam interessantes, prazerosas e articuladas com outros campos de conhecimentos. Dessa forma, este artigo busca evidenciar alguns resultados e reflexões, fruto das experiências pedagógicas que ocorreram com o protagonismo inicial do Desenho Técnico, ao ressaltar os benefícios tangíveis aprendizagens, articulações conceituais, percepções ampliadas, além de muita motivação, alegria, disposição e reminiscências, que são declarados pelos envolvidos, por intermédio das ações citadas. Dentre as implicações do estudo, sugere-se a necessidade de continuidade do trabalho sobre as possibilidades do Desenho Técnico, de modo que, possam favorecer as ações pedagógicas com a componente curricular de modo ampliado, tornando-a cada vez mais significativa, sobretudo diante de acadêmicos de engenharia.
\end{abstract}

Palavras - chave: Aprendizagem. Desenho Técnico. Conhecimento. Interdisciplinaridade.

\section{TECHNICAL DRAWING AND SIGNIFICANT PEDAGOGICAL TRAVELS: A LOOK AT LEARNING IN ENGINEERING COURSES}

\begin{abstract}
The pedagogical mediation of the curricular component Drawing technique is sometimes confused by some engineering students with the difficulties, as something "very annoying", meaningless, colorless, unattractive and lifeless. However, some interdisciplinary workshops, mini-courses and extension activities can be observed through some pedagogical actions in the classroom, on the contrary the opposite: beauty, sense, color, movement, creativity, art, conceptual integrations and much involvement, since the public participates actively in the elaboration of knowledge, establishing connections with other areas of action, with many important singular perceptions. It is possible, in a playful, participatory, dynamic, and contextualized way, to elaborate, to exemplify, to elaborate and to resize some graphic representations - projective drawings, based on some concepts and previous perceptions of students, which are present in daily life, in general, the following, content, symmetry, geometric sound, polyhedra, regular and uniform forms, angles, arcs, among others, through a
\end{abstract}


pedagogy supported by playfulness and creativity, since as activities become interesting, pleasurable and articulated with other fields of knowledge. In this way, this article seeks to show results and reflexes, the result of the pedagogical experiences that emerged with the initial protagonism of the Technical Drawing, highlighting the tangible benefits - learning, conceptual articulations, expanded perceptions and motivation, joy, disposition and reminiscences, which are declared by those involved, through the aforementioned actions. Opportunities for study, it is suggested to implement curricular tasks in a graphical way, so that, it can favor pedagogical actions with a curricular component in an expanded way, becoming once more significant, especially in front of engineering academics.

Key - words: Learning. Technical drawing. Knowledge. Interdisciplinarity.

\section{DISEÑO TÉCNICO Y PERCURSOS PEDAGÓGICOS SIGNIFICATIVOS: UNA MIRADA SOBRE APRENDIZAJE EN CURSOS DE INGENIERÍA}

\section{Resumen}

La mediación pedagógica del componente curricular Técnica de diseño a veces es confundida por algunos estudiantes de ingeniería con las dificultades, como algo "muy aburrido", sin sentido, sin color, sin atractivo, sin atractivo y sin vida. Sin embargo, algunos talleres interdisciplinarios, minicursos y actividades extensionistas pueden ser observados a través de algunas acciones pedagógicas en el aula, al contrario de lo contrario: belleza, sentido, color, movimiento, creatividad, arte, integraciones conceptuales y muy implicación, ya que el público participa activamente en la elaboración del conocimiento, estableciendo conexiones con otras áreas de acción, con muchas percepciones singulares importantes. Es posible, de forma lúdica, participativa, dinámica y contextualizada, elaborar, ejemplificar, elaborar y redimensionar algunas representaciones gráficas diseños proyectivos, basados en algunos conceptos y percepciones previas de los alumnos, presentes en el cotidiano, en general, el siguiente, contenido, simetría, sonidos geométricos, poliedros, formas regulares y uniformes, ángulos, arcos, entre otros, a través de una pedagogía apoyada en el lúdico y en la creatividad, pues las actividades se vuelven interesantes, agradables y articuladas con otros campos del conocimiento. De esta forma, este artículo busca mostrar resultados y reflejos, fruto de las experiencias pedagógicas que emergieron con el protagonismo inicial del Dibujo Técnico, destacando los beneficios tangibles - aprendizaje, articulaciones conceptuales, percepciones y motivaciones expandidas, alegría, disposición y reminiscencias, declarados por los involucrados, a través de las acciones arriba mencionadas. Las oportunidades de estudio, se sugiere la implementación de tareas curriculares de forma gráfica, para que pueda favorecer acciones pedagógicas con un componente curricular de forma ampliada, tornándose una vez más significativa, especialmente ante los académicos de ingeniería.

Palabras clave: Aprendizaje. Diseño técnico. Conocimiento. Interdisciplinariedad. 


\section{INTRODUÇÃO}

Por muito tempo, os estudantes foram concebidos como seres passivos e que apenas deveriam ouvir e reproduzir o que ouviam ou viam quando solicitados. Esse perfil de estudante cabe nos dias atuais? Faz sentido um "estudante" que não interaja com a vida cotidiana, seja em que instância for? Então, como manter "aquele jeito" de "ensinar" Desenho Técnico, se não reflete, não interage, não dialoga ou não articula cada vez mais com os dias atuais?

Sabe-se que, desenvolver essas diferentes formas de mediar o conhecimento representa um desafio para os educadores, sobretudo quando se tenta articular o que aparentemente é impossível, tal como o Desenho Técnico com componentes curriculares cotidianamente distintos, quando numa abordagem inicial não sejam percebidas algumas conexões importantes para se estabelecer uma mediação pedagógica significativa.

A união do raciocínio lógico com a criatividade sempre foi responsável por grandes avanços do homem. Desde as primeiras edificações, túmulos piramidais, objetos e variados utensílios para o trabalho doméstico e para lavoura. Da lâmpada elétrica aos atuais smartphones, passando pelo avião e pelo relógio de pulso, significativas inovações são e foram alcançadas com base nessa combinação e, por conseguinte, mediante um desenho técnico, um projeto gráfico ou um simples esboço que consistem num dos fundamentos do Desenho Técnico, tal como conhecido na contemporaneidade.

É preciso compreender, que é necessário que os estudantes consigam responder "para que" estão aprendendo tal conteúdo, assim como, os docentes mediadores possam responder "para que" estão mediando, a fim de que estabeleçam vínculos entre universidade e vida e, além disso, vejam relações entre conteúdos das diversas componentes curriculares, uma vez que, como se sabe, o conhecimento proporcionado pelo Desenho Técnico não é estanque e que com isso, podem aprender, percebendo, então, que há fundamentos, interdisciplinaridade, articulações de conhecimentos, sentido, coerência e necessidades prévias para sua compreensão.

Dessa forma, o artigo ora apresentado tem como finalidade evidenciar alguns resultados e reflexões, fruto das experiências pedagógicas que ocorreram com o enlace desencadeador do Desenho Técnico, ao ressaltar os benefícios tangíveis - aprendizagens, articulações conceituais, percepções ampliadas, além de muita motivação, alegria, disposição e colocações significativas realizadas pelos estudantes de engenharia envolvidos.

O artigo está estruturado da seguinte maneira: introdução, protocolo metodológico, 
perfil do público alvo e ambiente de trabalho, evidências de aprendizagens, algumas assertivas fundamentais sobre Desenho Técnico, Desenho Técnico e Educação, algumas ponderações acerca da componente curricular Desenho Técnico e possibilidades, resultados e discussões, considerações finais e referências de apoio. São seções ou/e subseções pensadas para esclarecer melhor um percurso de trabalho efetivado.

\section{METODOLOGIA}

Para realização do trabalho, adotou-se a pesquisa qualitativa, que segundo Godoy (1995), tem o ambiente natural como fonte direta de dados e o pesquisador como instrumento fundamental na pesquisa. Esse tipo de trabalho segundo o autor tem como preocupação fundamental o estudo e análise dos dados valorizando o contato direto entre o pesquisador e o ambiente pesquisado. No caso do trabalho em questão, foi realizado com estudantes do Curso de Engenharia Sanitária e Ambiental $-1^{\circ}$ semestre de uma instituição pública estadual e do Curso de Engenharia de Produção - $3^{\circ}$ semestre de uma instituição particular, ambas situadas na cidade de Alagoinhas - BA.

Entende-se que, pensar uma tomada de dados é uma ideia vinda sempre que se pensa em pesquisa e em necessidades pedagógicas. É o que diz D’Ambrósio (2006, p. 102). Para ele a pesquisa qualitativa está focada na pessoa, com toda sua complexidade e na sua interação com o meio sociocultural e natural. Sendo que nesse tipo de pesquisa "o principal é um desempenho qualitativo para se abordar uma questão" (D'AMBRÓSIO 2006, p. 103).

Dessa forma, o trabalho realizado percorreu os seguintes caminhos:

- Busca por publicações referentes ao tema - O Ensino do Desenho Técnico e suas possibilidades;

- Observações permanentes acerca dos conhecimentos de Desenho Técnico apresentados pelos estudantes no decorrer de 60 aulas ministradas e da prática de exercícios gráficos complementares;

- Sondagens que duraram onze encontros com 04 aulas semanais durante o semestre com as turmas, onde algumas atividades referentes aos conteúdos de Desenho Técnico foram aplicadas, muitas delas, totalmente voltadas para a área de conhecimento específico do curso;

- Quatro encontros durante o semestre, com 04 horas aulas semanais foram utilizados para aplicação das verificações das aprendizagens, como exigência de protocolos institucionais. 
Especificamente, mediante exposições dialogadas com os acadêmicos, foram trabalhadas nas turmas de engenharia citadas, questões ligadas diretamente aos cursos tais como: o que é visão espacial, o que é Desenho Técnico; diferenças entre o Desenho Técnico e o Desenho Artístico; como um desenho técnico é elaborado; espaço para desenho; legenda; normas; equipamentos para desenho técnico (papel, lápis, régua, compasso, transferidor, escalímetro, borracha), dentre outras abordagens.

Dessa forma, as atividades foram ministradas por meio de aulas expositivas com o objetivo de articular conceitos, fundamentos gráficos, traçados, projeções gráficas e alguns conteúdos específicos do Desenho Técnico, tais como: ponto, linhas, retas; semirretas; plano; superfície, ângulos, arcos, círculos, circunferências, formas regulares e irregulares, simetria e assimetria, figuras geométricas planas; sólidos geométricos; prismas; pirâmides; sólidos de revolução, sólidos geométricos truncados, vazados; perspectivas isométrica, cavaleira e cônica; Desenho Técnico projetivo e não projetivo e outros conteúdos com larga aplicação nas engenharias.

Figuras 01, 02 e 03 - Elaborações visuais realizadas pelos estudantes - fundamentações conceituais: bidimensionalidades, tridimensionalidades, relevo, sombras, sobreposições, transparências etc.
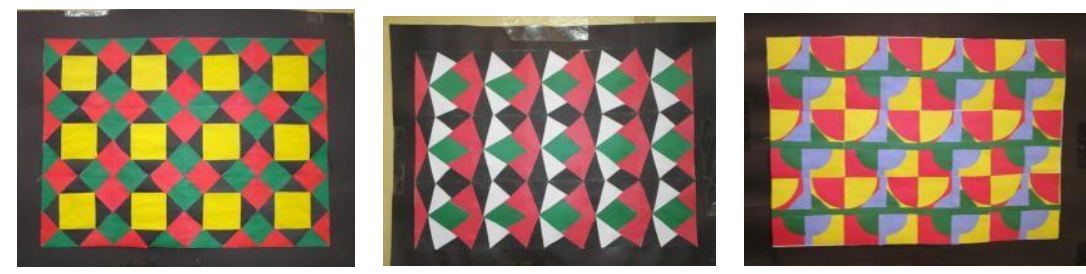

Fonte: acervo do autor (2017/2018)

As aulas ocorreram com os conteúdos citados, ao longo dos semestres, utilizando-os conforme as abordagens de cada encontro em sala de aula, apoiados materialmente com - quadro amplo para demonstrações, piloto, monitor de vídeo, slides, os instrumentos de desenho, ferramentas AutoCAD 2D e 3D, bidimensional e tridimensional respectivamente, conforme necessidades planejadas.

\section{PERFIL DO PÚBLICO ALVO E AMBIENTE DE TRABALHO}

O trabalho foi realizado com estudantes do Curso de Engenharia Sanitária e Ambiental - $1^{\circ}$ semestre de uma instituição pública estadual e do Curso de Engenharia de Produção - $3^{\circ}$ semestre de uma instituição particular. Alguns dados foram obtidos nas respectivas secretarias acadêmicas das instituições em foco.

As atividades ocorreram semanalmente durante os semestres acadêmicos, por meio de 
uma carga horária de 03 (três) aulas (instituição particular) e de 04 (quatro) aulas (instituição pública). As salas de aula não são equipadas com pranchetas e banquetas, possuem apenas mesas e cadeiras convencionais do tipo escolar, que propiciam razoavelmente algum conforto para realização das atividades. São bem iluminadas, limpas, climatizadas e amplas. As duas turmas somadas compuseram média de 28 (vinte e oito) estudantes, com frequência regular, durante realização dos trabalhos.

No Curso de Engenharia Sanitária e Ambiental a turma é constituída por 34 (trinta e quatro) estudantes, sendo 21 do sexo feminino e 13 do sexo masculino, com faixa etária entre 19 e 33 anos. Por se tratar de curso ofertado no turno noturno, a maioria $85 \%$ dos estudantes são trabalhadores de distintas esferas - funcionários públicos, industriários, comerciários, ferroviários, autônomos etc. Vale ressaltar, que dentre os 34 estudantes, apenas 08 (oito) tem formações técnicas variadas, obtidas em escolas estaduais, particulares e/ou federais e, por isso, apresentam algum conhecimento acerca do Desenho Técnico.

No Curso de Engenharia de Produção a turma é constituída por 24 (vinte e quatro) estudantes, sendo 09 do sexo feminino e 15 do sexo masculino, com faixa etária entre 17 e 29 anos. Trata-se também de um curso ofertado no turno noturno e, $95 \%$ dos estudantes são trabalhadores de variadas procedências - feirantes, ferroviários, autônomos, comerciários, micro empresários etc. Na turma trabalhada, apenas 02 (dois) estudantes apresentaram algum conhecimento em Desenho Técnico por terem realizado curso técnico numa escola técnica federal.

\section{EVIDÊNCIAS DE APRENDIZAGENS}

Para efetivação das atividades pedagógicas em sala de aula, organiza-se a apresentação inicial das ações com os estudantes, esclarecem-se os assuntos, os conteúdos e materiais desenho necessários para o encontro por meio de diálogos sobre os objetivos e propósitos para o ciclo de atividades.

Costumeiramente, são orientados para perceberem as imagens do ambiente imediato da sala de aula, o corpo e formas visuais em geral de modo livre. Posteriormente, solicita-se que observem objetos nas suas respectivas residências, locais de trabalho, na cidade, nos percursos na cidade até a chegada nas instituições de estudo para que possam desenvolver cada vez mais a observação, a atenção e o conhecimento geométrico que já possuem para agregar aos propósitos dos trabalhos sugeridos no decorrer dos semestres. 
Em seguida, após solicitação para que observassem o espaço da sala de aula, estabelece-se um tempo determinado, dando-se a seguir um sinal para que possam começar alguns diálogos e comentários acerca de algumas imagens ou objetos presentes no ambiente, quando cada estudante poderá acrescentar algum comentário sobre o que observou em termos de formas visuais e as informações geométricas implícitas no ambiente e/ou no objeto analisado.

Os participantes se empenham nas atividades propostas, na formulação de alguns comentários e, volta-se a interferir nos diálogos para solicitar que olhem mais uma vez para o espaço da sala de aula, para que possam ampliar os comentários do grupo com relação à dinâmica das atividades em curso. Nesse momento, expõem-se por meio de desenhos projetivos realizados no quadro da sala de aula algumas atividades que articulam o Desenho Técnico com as observações feitas para favorecer a percepção de algumas possibilidades articuladoras com áreas de conhecimentos distintas e o Desenho Técnico propriamente dito.

No decorrer das atividades realizam-se comentários acerca de alguns conceitos geométricos, que se fizeram presentes nos exercícios de "olhar" e "ver" realizados, com o propósito de esclarecer que tais aspectos que permeiam o trabalho serão utilizados como parte das criações e que as atividades deverão servir para descobrir referências geométricas no ambiente, no cotidiano, na vida em geral. Esclarecendo melhor a questão sobre percepção e visão do ambiente, afirma Aumont (1993, p. 14) o seguinte:

\begin{abstract}
A visão, a percepção visual, é uma atividade complexa que não se pode, na verdade, separar das grandes funções psíquicas, a intelecção, a cognição, a memória, o desejo. Assim, a investigação, iniciada "do exterior", ao seguir a luz que penetra no olho, leva logicamente a considerar o sujeito que olha a imagem, aquele para quem ela é feita, o qual chamaremos de seu espectador.
\end{abstract}

Pelo exposto, depois de realizados alguns esclarecimentos e comentários, estimulamse os estudantes para que, a partir das informações, materiais de desenho disponíveis e solicitados que, mediante a imaginação criadora, elaborem atividades gráficas - desenhos, projeções ou esboços de acordo com as leituras visuais realizadas, que estejam em sintonia com as observações e conforme solicitado no momento, de modo que, apareçam nas atividades realizadas pelos estudantes de engenharia algumas representações de conceitos e elementos discutidos no encontro no que diz respeito ao conhecimento geométrico. Nesse momento, realizam esboços, desenhos projetivos com base nas observações efetivadas.

Dessa maneira, ampliam-se as aprendizagens, as discussões e diálogos sobre o assunto, permitindo-se assim, estabelecer conexões para os encontros seguintes, sempre perguntando 
algo comentado nos encontros anteriores, para percebermos assimilações, lembranças, interrelações dos conteúdos, dentre outros aspectos, com o propósito de estabelecermos aprendizagens significativas devidamente articuladas com as propostas de cada encontro, uma vez que, consideramos tais dados como resultados qualitativos que poderão favorecer planejamentos e projetos vindouros, assim como, com as atividades propostas em cada encontro pedagógico.

\section{ALGUMAS ASSERTIVAS FUNDAMENTAIS SOBRE DESENHO TÉCNICO}

Sabe-se que, o Desenho e seus fundamentos, como forma de comunicação é utilizado desde a Pré-História, nas primeiras civilizações, nos distintos períodos históricos subsequentes até a atualidade. Pode ser classificado como Desenho Técnico e como Desenho Artístico, dentre outras modalidades.

O Desenho Artístico consiste em toda forma de se colocar em quaisquer materiais ou suportes que se queira usar, as ideias e pensamentos que se possui e com total permissão criativa e liberdade expressiva para retratar o mundo da maneira que se vê, que se sente, que se observa, bem como a realidade, com todos os detalhes. É um desenho feito com liberdade e muita criatividade.

De acordo com Edson Dias Ferreira (2005), a cultura se expressa na produção autoral do artista e o desenho não deve estar desvencilhado, dos eixos discursivos da memória coletiva, da etnicidade, e de grupos de pertencimento em um ambiente espaço temporal. Destarte, a criação do artista é um instrumento da vida, um modo de entender quem o humano é e o lugar deste humano (ARNHEIM, 1962; apud FERREIRA, 2005).

Gomes (1996, p 13) define o Desenho como sendo uma das formas de expressão humana que melhor permite a representação das coisas tanto concretas quanto abstratas do mundo natural ou artificial em que vivemos.

De acordo com a enciclopédia BARSA (1982, p. 222-223), o Desenho é a arte de reproduzir sobre uma superfície bidimensional e por meio de linhas, objetos, ideias ou emoções. Ele precede a pintura, a escultura, a arquitetura e a gravura, sendo considerada uma arte básica. O desenho varia de acordo com a finalidade a que se destina.

Por sua vez, o Desenho Técnico, como o próprio nome diz, é realizado mediante regras e procedimentos. É importante que o desenhista siga normas técnicas de acordo com o segmento para o qual será necessário. Neste tipo de desenho, as formas usadas também são peculiares e precisam seguir as normas da Associação Brasileira de Normas Técnicas - 
ABNT.

Segundo Serra (2008), os fundamentos do Desenho Técnico são universais, independentemente da cultura e das legislações dos países, facilitando assim, a globalização do conhecimento. Por isso, o conhecimento das normalizações que rege a componente curricular do Desenho Técnico poderá complementar a formação do estudante de engenharia que o tem como instrumento indispensável para sua formação.

De acordo com Trinchão (2012 p. 9), a atividade de desenhar desenvolve possibilidades para controlar as próprias mãos e permite domar os olhos numa coordenação mútua. Para a autora o poder educativo do desenho como recurso pedagógico é importante por ser capaz de atuar na formação da imaginação do indivíduo.

Ainda para Trinchão (2012 p. 13) “A escrita e o desenho são meios de representação e expressão que comportam aperfeiçoamento e progressão, por incorporação dos componentes formal, estética, semiótica". Tecnicamente são passíveis de transmissão por ensino e aprendizagens sistemáticas e objeto de treino.

O Desenho é uma manifestação realizada com raciocínio, discernimento, método e criatividade, podendo promover ao ser humano o desenvolvimento das capacidades intelectuais e psicomotoras (TRINCHÃO, 2012, apud FIGUEIREDO 1982).

O Desenho enquanto campo de conhecimento poderá possibilitar ao educando o domínio do controle do corpo através dos movimentos provocados pelo exercício, que começam desde o modo de pegar no lápis, como apoiar a mão no papel, a postura do corpo em relação à cadeira e a mesa. Trinchão, 2012, apud Figueiredo (1982) ainda justifica que a compreensão do Desenho possibilita o desenvolvimento da motricidade criando assim autonomia.

Para Serra (2008, p. 54), “O Desenho Técnico é a única forma eficiente e segura de transmitir ideias e soluções para os projetos de qualquer ramo das engenharias". Por isso, os currículos dos cursos de engenharia possuem este componente curricular em sua programação e é uma ferramenta imprescindível para formação profissional dos engenheiros que utilizam o desenho para criar, transmitir, interpretar e analisar informações, é o que diz a autora, segundo (MORAES, 2016).

Nem só as habilidades motoras são suficientes para a realização de um bom desenho, a percepção visual é importantíssima para a execução de um desenho perfeito, assim como aprender ler e escrever, "aprender a ver e a desenhar é um modo muito eficiente de educar o sistema visual" (EDWARDS, 2002, p. 18), uma vez que, se utilize o desenho como meio de 
desenvolver as habilidades para a expressão gráfico-visual.

Em caráter interdisciplinar, o Desenho Técnico está aliado à Matemática e a Geometria e intimamente ligado a Arquitetura, a Astronomia, a Engenharia Militar, Civil e Náutica e, principalmente, à Indústria e ao ensino da leitura, escrita contagens e operações matemáticas. Tais campos profissionais exigiram mais a familiarização com a Geometria e a prática do Desenho foi o caminho natural dos cursos de caráter científico e literário. A Geometria, instrumentalizada pelo saber em Desenho individualmente ensinado se constituiu em uma forma privilegiada (TRINCHÃO, 2012, p.88).

Conforme Silva (2006), com o advento da Revolução Industrial, ocorreu a estandardização, que incluiu a padronização da fabricação em série de mercadorias. Houve a necessidade de normalizar procedimentos gráficos a fim de se criar uma forma única de interpretação de projetos para atender essas demandas. A Comissão Técnica da International Organization for Standardization (ISO) realizou esse processo em caráter de documento para ser aplicado no Desenho Técnico.

Ainda para o autor, o Desenho Técnico é considerado como aplicação dos princípios da expressão gráfica sistematizada, que obedece a regras estipuladas mundialmente, onde a comunicação de uma ideia, conceito ou projeto deve ser com critérios projetivos únicos, sem duplicidade de significados ou multiplicidade de interpretações.

É através do Desenho Técnico que os estudantes de engenharia podem descobrir relações gráficas e desenvolver o senso espacial construindo, desenhando, medindo, visualizando, comparando, transformando e classificando figuras. Ao trabalharmos dessa maneira estaremos contribuindo para a aprendizagem do Desenho Técnico.

As atividades geométricas poderão permitir também ao estudante identificar regularidades, buscar semelhanças e diferenças, perceber que as formas geométricas detêm um amplo campo de entendimento e elaborações com o Desenho Técnico.

O Desenho Técnico está implícito em toda parte como desenho da planta de uma casa ou de um terreno, nos objetos, roupas, acessórios, materiais cirúrgicos etc. Portanto, essa atividade requer habilidades e competências que envolvem semelhanças de figuras, proporcionalidades, métodos qualitativos e quantitativos para verificar se um determinado lado da casa ou do objeto em elaboração pode realmente ser daquele tamanho ou se deveria ser menor.

O Desenho Técnico é de fundamental importância para que o estudante de engenharia compreenda as aplicações nos cálculos mais sofisticados. O Desenho Técnico prima pela 
adoção de regras, medidas, valores geométricos propriamente entendidos.

Enfim, é preciso saber com clareza, quais as contribuições de cada um dos conteúdos do Desenho Técnico para os processos de desenvolvimento e aprendizagem dos estudantes das engenharias em particular, bem como, de todos que se coloquem à disposição para estudar mediante o Desenho Técnico.

\section{DESENHO TÉCNICO E EDUCAÇÃO: ALGUMAS PERCEPÇÕES}

Numa compreensão geral, o Desenho Técnico é um suporte gráfico ligado a representações bidimensionais e tridimensionais, por servir para compreensão de projeções em planos, com o auxílio de pontos, linhas e formas planas e não planas e, envolve basicamente conceitos da Geometria, ramo da Matemática.

Para estudar Desenho Técnico o estudante da escola básica, de universidades ou de cursos técnicos ou profissionalizantes, precisa ter um conhecimento básico de Desenho em geral, Matemática e Geometria, por conseguinte, sendo que a realização de atividades dessa natureza depende de um conhecimento mínimo, mas que poderá facilitar o entendimento desse conhecimento específico.

No que concerne a Educação, sabe-se que foi concebida mediante ações reflexivas, almejando-se um ensino que possibilitasse aos estudantes proceder a análises, discussões, conjecturas, apropriação de conceitos, formulação de idéias, ou seja, de amplitudes conceituais significativas e a percepção da vida numa perspectiva ampliada.

Para tanto, é preciso que haja projetos e ações com características integracionistas, que possam explicitar a articulação do Desenho Técnico com a Educação, como criação, como reflexão e transformação do mundo subjetivo e objetivo, como resultado prático de uma produção conjunta entre a mão, o olho e a consciência individual e coletiva, ainda que, mediante uma forma particular e subjetiva de percepção de dados de aprendizagens geométricas, que considerem os conteúdos estruturantes e os fundamentos do Desenho Técnico enquanto área de conhecimentos, conforme as necessidades pedagógicas de quem aprende. A este respeito, vejamos o que é dito por Wucius Wong (1998, p. 15).

O desenho é um processo de criação visual que tem propósito. Diversamente da pintura e da escultura, que constituem a realização das visões e sonhos pessoais dos artistas, o desenho preenche necessidades práticas. Um trabalho de desenho gráfico deve ser colocado diante do olhar do público e transmitir uma mensagem predeterminada. [...] sua criação deve ser não somente estética, mas também funcional, ao mesmo tempo em que reflete ou orienta o gosto de seu tempo. [...] o desenho é prático. 
Dessa forma, pode-se perceber o quanto o Desenho Técnico poderá influenciar no desenvolvimento da intuição e imaginação. Sobre a importância do conhecimento geométrico advindo do Desenho Técnico, vale ressaltar o que é dito por Antonio Pedro Alves de Carvalho (2001, p.16):

\begin{abstract}
A geometria surge como expressão de grandezas que podem ser representadas com exatidão, guiadas por quantidades e posições, que formam o embrião do Desenho Técnico, hoje imprescindível para a confecção dos artefatos industrializados. Estas áreas de atuação do Desenho, a arte e a ciência, mantêm-se até hoje como tipos por vezes conflitantes de expressão, possuindo, no entanto, inúmeros pontos de contato.
\end{abstract}

Como se percebe, as atividades proporcionadas pelo Desenho Técnico poderão inclusive, proporcionar a expansão do universo cultural dos estudantes de engenharia, abrindo espaço para a participação social, onde aprender poderá ser um caminho profícuo a ser vislumbrado em sala de aula, ao se ampliar as possibilidades de comunicação. Nessa perspectiva, os estudantes de engenharia podem se tornar partícipes de descobertas e protagonistas em um processo de investigação que seja constante em sala de aula.

Buscam-se aproximar as elaborações dos estudantes de engenharia com padrões de realização não habituais, justamente para aguçar o olhar diferenciado e a criatividade com relação ao conhecimento em Desenho Técnico, pois tal perspectiva poderá ser assegurada ao se trabalhar com informações, estratégias e metodologias que enfatizem as realizações baseadas no desenho presentes no entorno, a bem da participação dos estudantes de engenharia na sociedade como cidadãos informados, críticos, integrais e articulados.

Por meio das experiências vivenciadas, podem-se perceber o significado e a importância da aprendizagem através do Desenho Técnico num contexto lúdico e, por conseguinte, com criatividade no cotidiano, o que nos permite perceber dados qualitativos para reflexões e previsões para encontros posteriores.

Cabe-nos ressaltar que este é um tema de extrema relevância para o processo de ensino/aprendizagem por intermédio do Desenho Técnico enquanto campo de conhecimento e/ou componente curricular.

Reiteramos que, projetos de pesquisa, extensão e ensino podem se constituir num importante fator de estímulo para trabalhos que priorizam atividades pedagógicas que articulem o Desenho Técnico com outras áreas de estudos, para públicos distintos ou específicos, por intermédio de metodologias que sejam ativas e prazerosas, que possam ressaltar o Desenho Técnico com possibilidades de diálogos interdisciplinares, com as 
profissões em geral e com as engenharias em particular, como se pretende na atualidade.

\section{RESULTADOS E DISCUSSÕES}

O trabalho se iniciou, com a definição do tema - O ensino do Desenho Técnico e suas possibilidades de articulações. Como um dos objetivos propostos, buscou-se também, publicações acerca do assunto, para o enriquecimento da pesquisa.

Foram feitas observações no decorrer das aulas, com o propósito de adquirir informações sobre como os estudantes das duas turmas dos cursos de engenharias citadas detinham o conhecimento sobre o Desenho Técnico, suas implicações, dificuldades ou facilidades, ou seja, o grau de compreensão sobre a componente curricular.

Os conteúdos constantes nas ementas dos cursos nas duas instituições, eram similares e completamente voltados para as necessidades formativas dos estudantes e, com isso, possibilitou observar no decorrer das aulas que alguns estudantes apresentavam dificuldades, aversão, medo ou antipatia pelo Desenho Técnico, conforme manifestavam oralmente.

Tais constatações foram compreendidas posteriormente, quando se percebeu por meio de depoimentos, que estes estudantes, em maioria, jamais tinham trabalhado na escola básica com instrumentos de desenho e, como tal, desconheciam as propriedades da componente curricular, além de dificuldades gritantes em manusear os instrumentos específicos de desenho.

Todavia, com o decorrer das ações e por meio dos conteúdos ministrados, os estudantes identificavam e construíam figuras geométricas, representando pontos, linhas e suas configurações conforme necessidades do Desenho. Traçavam retas, semirretas, segmentos de retas, as principais formas geométricas planas e espaciais, visualizaram alguns sólidos, bem como os de revolução, os truncados e os vazados, construíram esboço de planta baixa de determinado ambiente, interpretaram algumas outras plantas baixas, desmistificandose assim, alguns medos, dificuldades, rejeições etc.

Para tanto, aplicou-se um questionário acerca do Desenho Técnico e as relações com alguns aspectos sociais e educacionais importantes para pesquisa - histórico, importância, aprendizagem, estudos anteriores etc.. Os estudantes responderam individualmente e de forma sucinta, com base na experiência pessoal, sem consultas a internet, de modo que a devolução fosse logo posterior a aplicação.

De posse dos questionários devidamente respondidos, analisou-se mediante abordagem qualitativa, descrevendo-se os fatos apresentados intuitivamente pelos estudantes 
quanto às relações do Desenho Técnico com o contexto sócio-educacional, se os estudantes percebiam essas interrelações e se as dificuldades ou facilidades em assimilar Desenho Técnico eram decorrentes do processo de ensino e de aprendizagem da componente curricular de um momento anterior à chegada deles ao curso superior ou não.

Durante as explanações dos conteúdos, foram utilizados recursos áudio visuais como: monitor para apresentação de slides, lousa ampla da sala de aula, piloto. Os estudantes utilizavam caderno de desenho formato A-3 margeado, com os instrumentos básicos para desenho. Todos portavam os materiais solicitados no primeiro encontro do semestre, facilitando assim o andamento das atividades propostas.

As atividades realizadas pelos estudantes foram basicamente - construções de formas geométricas mediante os principais sistemas projetivos, esboço de planta baixa de determinado ambiente, interpretação de algumas plantas baixas prontas, análises e traçados gráficos conforme oferta do encontro em sala de aula. Essas atividades de desenho foram realizadas no papel formato A-3 margeado, com o auxílio do lápis e outros utensílios necessários para realização das mesmas.

Durante as realizações das atividades, foi observado que os estudantes identificavam com regular dificuldade, conceitos considerados essenciais para compreensão do Desenho Técnico e, muitos deles, apresentavam dificuldades para manusear os esquadros, transferidores, compassos etc.

Todavia, vale ressaltar também, que alguns estudantes apresentavam simpatia pelas atividades em curso, fato que, servia de motivação para o docente pesquisador e também para outros estudantes que assimilavam com mais rapidez, atuando em alguns momentos como monitores para turma.

Foi observado também, que alguns estudantes eram mais criativos e habilidosos na realização das atividades, outros, por sentirem alguma dificuldade, medo e até mesmo, certa negligência, pediam auxílio o tempo todo, tanto ao docente, quanto aos colegas mais inseridos na proposta para que pudessem se desempenhar nas atividades e, principalmente, por se tratar de algo que era pra ser avaliado quantitativamente, para andamento do curso.

Algumas observações foram feitas informalmente e continuamente, no decorrer das aulas ministradas. Os estudantes não foram informados de tais observações, pois as mesmas aconteciam naturalmente, sem ter que mudar alguma rotina no trabalho, o que pode acontecer, quando essa observação é feita em um ambiente onde o pesquisador está inserido.

Analisou-se o comportamento dos estudantes enquanto assistiam às aulas de Desenho 
Técnico; quais eram suas expectativas diante de tais conteúdos; como recebiam as atividades propostas; se conseguiam encontrar estratégias para resolver o que era solicitado ou se esperavam respostas prontas para apenas copiarem no momento da correção, ou seja, se participavam ativamente das aulas ou simplesmente eram meros expectadores.

As atividades aplicadas foram relacionadas aos conteúdos da componente curricular Desenho Técnico, sempre voltados para os cursos de engenharia conforme esclarecido anteriormente.

Desde a parte introdutória e teórica sobre o Desenho Técnico, os estudantes dialogaram sobre questões que articulavam o Desenho Técnico com distintas profissões e ofícios, histórico, relações com o curso que realizavam, para que os presentes pudessem falar a respeito de suas vivências, aprendizagens ou conhecimentos prévios sobre o assunto. Visualizavam algumas imagens e tópicos escritos em slides, ouviam o que era explicado e participavam oralmente comentando, perguntando ou respondendo algo sobre o assunto.

\section{CONSIDERAÇÕES FINAIS}

Considerando-se os questionamentos e percepções anteriores, é que se pensa na possibilidade de articulação do Desenho Técnico enquanto campo de conhecimentos, componente curricular e/ou área de estudos, com todos os seus desdobramentos expressivos, como aliado pedagógico numa prática que se quer dinâmica, viva, lúdica e motivadora de aprendizagens significativas.

Desse modo, entende-se o Desenho Técnico como linguagem universal, que poderá promover uma visão de mundo ampliada, que incorpora mecanismos para desrobotizar a aprendizagem, como uma atividade primária essencial da vida estudantil dos acadêmicos em engenharia e, de preferência, integrado aos aspectos lúdicos ${ }^{1}$ e prazerosos que devem se apresentar em tais mediações pedagógicas.

Em outras palavras, as possibilidades expressivas do Desenho Técnico, quando adotado de forma articulada na prática pedagógica objetivando a aprendizagem dos estudantes de engenharia poderá trazer mais conhecimentos e ser mais eficaz como portadora de informação e sentido. Isto porque a aprendizagem deve ser também um convite ao exercício prático de aprender a ver, observar, ouvir, tocar, atuar e refletir geometricamente. Assim, os estudantes poderão perceber melhor as informações que lhes são apresentadas. No que diz

\footnotetext{
${ }^{1}$ Relativos a jogos, brinquedos, divertimentos, contrapartidas inspiradas nas linguagens artísticas, comportamentos, etc...
} 
respeito às teorias enquanto alimento para prática pedagógica, vejamos o que é dito por D’Ambrósio (2006, p. 79).

[...] Entre teoria e prática persiste uma relação dialética que leva o indivíduo a partir para a prática equipado da teoria e a praticar de acordo com essa teoria até atingir os resultados desejados. Toda teorização se dá em condições ideais e somente na prática serão notados e colocados em evidencia certos pressupostos que não podem ser identificados apenas teoricamente. Isto é, partir para a prática é um mergulho no desconhecido.

Pelo exposto, verifica-se que ações com perfis integradores - teoria e prática poderão contemplar os objetivos integracionistas do Desenho Técnico, uma vez que, devem ser compreendidas em função da curiosidade, interesse e envolvimento que foram manifestados pela maioria dos estudantes no decorrer das ações empreendidas, além, evidentemente, dos resultados práticos evidenciados, sem prejuízo da qualidade gráfica pretendida. Isso poderá permitir propiciar a tomada de consciência da existência de uma produção genuína, real e concreta, em permanente elaboração acerca do conhecimento proporcionado pelo Desenho Técnico.

Diante da limitação da oferta de conhecimentos sobre Desenho Técnico na escola básica conforme manifestado pelos estudantes participantes da pesquisa, acredita-se que, programas de cursos presenciais para professores, voltados para a melhor utilização dos recursos didáticos disponíveis, que sejam também concebidos tendo como base os princípios de uma proposta articuladora e interacionista, podem ser considerados numa formação continuada de professores, além de cursos à distância, com web cursos, web conferências e $w e b$ atendimentos que propiciem de fato o estudo e a reflexão constante acerca daquilo que se propõe a fazer de melhor em sala de aula, com ações desenvolvidas pelo conjunto de professores.

Tais capacitações podem ocorrer também, para que os professores num processo formativo permanente possam incorporar mais habilidades necessárias para o seu exercício profissional com Desenho Técnico e, consequentemente, encontrar sentido para o que se "ensina" e se "aprende" devidamente associado com a vida em geral, uma vez que, diante das colocações dos estudantes, pode-se até mesmo, questionar a formação do "mediador", de quem se propõe a levar adiante tais mediações e, qual é de fato a formação de quem desempenha esse papel pedagógico com Desenho Técnico.

Desse modo, a percepção atual que se tem sobre o Desenho Técnico não deve contemplar nem um ensino dirigido e baseado em modelos prontos, nem a liberdade 
completa, sem nenhuma ação do mediador. Trabalha-se com uma visão de linguagem, de comunicação, formada por elementos próprios, que estruturam uma forma de expressão ampla, refinada, necessária e rica, desde que bem ministrada.

Teve-se também, durante a pesquisa, a oportunidade, de reformulação e ajustes de alguns pontos do projeto para melhor andamento das ações, de dialogar com autores que elegeram o Desenho Técnico como objeto de trabalho, o que nos fez enriquecer significativamente as noções que se tinha inicialmente sobre o assunto.

O processo de conhecimento dos envolvidos esteve diretamente relacionado com a ampliação e reformulação do conhecimento do mediador. Houve inúmeras oportunidades de muitas aprendizagens recíprocas e, ao final, foi possível perceber que ainda há muito a aprender. Constatou-se que não basta ter um curso superior, mas que é preciso formação específica, capacitações regulares ao longo da vida profissional para que a mediação com o Desenho Técnico ocorra de maneira eficaz. 


\section{REFERÊNCIAS}

AUMONT, J. A imagem. Campinas: Papirus, 1993.

CARVALHO, A. P. A. O ensino do desenho no mundo da informática. Salvador-BA: Universidade Federal da Bahia. Faculdade de Arquitetura, Quarteto, 2001.

D’AMBRÓSIO, U. Educação Matemática: da teoria à prática. 13. ed. Campinas, SP: Papirus, 2006.

EDWARDS, R. Si. Piaget e a Matemática. Universidade Tecnológica Federal do Paraná UTFPR Programa de Pós-Graduação em Ensino de Ciência e Tecnologia - PPGECT. Curitiba - PR, 2002.

ENCICLOPÉDIA BARSA. Rio de Janeiro; São Paulo: Britânica do Brasil Publicações Ltda. v. $6,1982$.

FERREIRA, Edson Dias. Do desenho das Belas Letras à livre expressão no desenho da escrita. Salvador: EdUFBA. v. 1, 2005. (estudos interdisciplinares em desenho)

GODOY, A. S. Pesquisa qualitativa. Disponível em:

www.producao.ufrgs.br/arquivos/. 1995. Acesso em10/11/14

GOMES, N. A. B. Tratado de geometria por meio do desenho técnico. Disponível em: <educere.bruc.com.br/arquivo/pdf1995/1996_8309.pdf> Acesso em 15/04/2018.

MORAES, J. C; CHISTÉ, P. S. O ensino do desenho técnico mediado pela matemática, história da arquitetura e computação gráfica. São Paulo- SP 13 a 16 de julho de 2016. Encontro Nacional de Educação Matemática.

SERRA, S. M. B. Apostila do departamento de engenharia civil da UFSCar. 2008.

Disponível em: <livresaber.sead.ufscar.br:8080/jspui/bitstream> acesso em 11/04/2017.

SILVA, R. Y. S. Apostila do departamento de engenharia civil da UFPEL. v. 2, 2006. Disponível em: <livresaber.sead.ufspel.br:8080/jspui/bitstream> acesso em 11/04/2018.

TRINCHÃO, Gláucia Maria Costa (org). Do desenho das Belas Letras à livre expressão no desenho da escrita. Salvador: EdUFBA. v. 3, p 09-88, 2012. (Coleção estudos interdisciplinares em desenho).

WONG, W. Princípios de forma e desenho. São Paulo: Martins Fontes, 1998. 